OPEN ACCESS

Edited by:

Dominique Sanglard, Université de Lausanne, Switzerland

Reviewed by: Diego Fabian Gomez-Casati, National University of Rosario,

Argentina

Gary Moran,

Trinity College Dublin, Ireland

*Correspondence: Sneh Lata Panwar sneh@mail.jnu.ac.in

Specialty section: This article was submitted to

Infectious Diseases,

a section of the journal

Frontiers in Microbiology

Received: 14 March 2019 Accepted: 18 June 2019

Published: 09 July 2019

Citation:

Ror S and Panwar SL (2019) Sef1-Regulated Iron Regulon

Responds

to Mitochondria-Dependent Iron-Sulfur Cluster Biosynthesis

in Candida albicans.

Front. Microbiol. 10:1528. doi: 10.3389/fmicb.2019.01528

\section{Sef1-Regulated Iron Regulon Responds to Mitochondria-Dependent Iron-Sulfur Cluster Biosynthesis in Candida albicans}

\author{
Shivani Ror and Sneh Lata Panwar* \\ Yeast Molecular Genetics Laboratory, School of Life Sciences, Jawaharlal Nehru University, New Delhi, India
}

Iron homeostasis mechanisms allow the prime commensal-pathogen Candida albicans to cope with the profound shift in iron levels in the mammalian host. The regulators, Sef1 and Sfu1 influence activation and repression of genes required for iron uptake and acquisition by inducing the expression of iron regulon genes in iron-deplete conditions and inactivating them in iron-replete condition. Our study for the first time shows that $C$. albicans coordinates the activation of the iron regulon with the mitochondrial use of iron for Fe-S cluster biosynthesis, a cellular process that is connected to cellular iron metabolism. We took advantage of a mutant defective in mitochondrial biogenesis $(\mathrm{fzO} \Delta / \Delta)$ to assess the aforesaid link as this mutant exhibited sustained expression of the Sef1 iron regulon, signifying an iron-starved state in the mutant. Our analysis demonstrates that mitochondrion is pivotal for regulation of $\mathrm{Fe}-\mathrm{S}$ cluster synthesis such that the disruption of this cellular process in $f z 01 \Delta / \Delta$ cells lead to excessive mitochondrial iron accumulation and reduced activity of the Fe-S clustercontaining enzyme aconitase. Sef1 responds to defective Fe-S cluster synthesis by regulated changes in its subcellular localization; it was retained in the nucleus resulting in the induced expression of the iron regulon. We predict that the mitochondrial Fe-S assembly generates a molecule that is critical for ensuring iron-responsive transcriptional activation of the Sef1 regulon. All told, our data marks Fe-S biogenesis as a mechanism that meshes cellular iron procurement with mitochondrial iron metabolism resulting in regulating the Sef1 regulon in $C$. albicans.

Keywords: iron homeostasis, mitochondria, iron-sulfur cluster, Sef1, Candida albicans, iron regulon, FZO1

\section{INTRODUCTION}

Candida albicans is a fungal commensal-pathogen that makes up the human microbiome and is the fourth leading cause of nosocomial bloodstream infections in immunocompromised human hosts (Brown et al., 2012). Iron is an essential micronutrient that influences the virulence and pathogenesis of C. albicans (Fourie et al., 2018). The gastrointestinal tract (GI), the commensal niche of this pathogen, remains enriched in iron due to non-absorption of dietary iron and may 
reach toxic levels in certain situations (McCance and Widdowson, 1938; Miret et al., 2003). On the contrary, in its pathogenic lifestyle C. albicans faces scarcity of iron in the blood (Martin et al., 1987). A number of studies show that C. albicans deploys sophisticated mechanisms to acquire iron from the host in iron-deficient environments, while safeguarding itself from iron toxicity in iron-replete regions. Thus, survival of C. albicans in the host is dependent on its ability to maintain intracellular iron homeostasis by meticulously regulating iron acquisition, utilization and storage (Chen et al., 2011).

A tripartite system of transcription factors, Sef1 ( $\mathrm{Zn}_{2} \mathrm{Cys}_{6}$ DNA-binding protein), Sful (GATA factor), and Hap43 (CCAAT binding complex) regulate iron homeostasis in C. albicans (Figure 1) These transcription factors not only regulate each other but also control expression of iron uptake (Sef1, Sfu1) and iron utilization (Hap43) genes, collectively referred to as the iron regulon, thereby providing selective advantage to this fungus in environments with fluctuating iron levels (Chen et al., 2011). In iron-scarce situations, the increased expression of Sef1 and its activation by Ssn3 (Chen and Noble, 2012) allows the translocation of Sef1 to the nucleus resulting in the expression of genes that assist iron uptake and acquisition. Sef1 also induces Hap43 expression, which represses Sful and irondependent processes (Chen et al., 2011). Iron sufficiency relieves the repression on Sfu1, enabling it to physically associate with Sef1, thus preventing nuclear localization of Sef1 and activation of iron-regulon genes (Chen and Noble, 2012).

In Saccharomyces cerevisiae, the control of cellular iron homeostasis is mediated by the transcription factor Aft1 (Rutherford et al., 2005). The role of mitochondria and their $\mathrm{Fe}-\mathrm{S}$ cluster machinery in regulating various iron-dependent cellular processes in eukaryotes has been established (Lill and Mühlenhoff, 2006). The importance of Fe-S cluster biogenesis to cellular iron metabolism has been demonstrated by creating mutants that are defective in this cellular process. These mutants

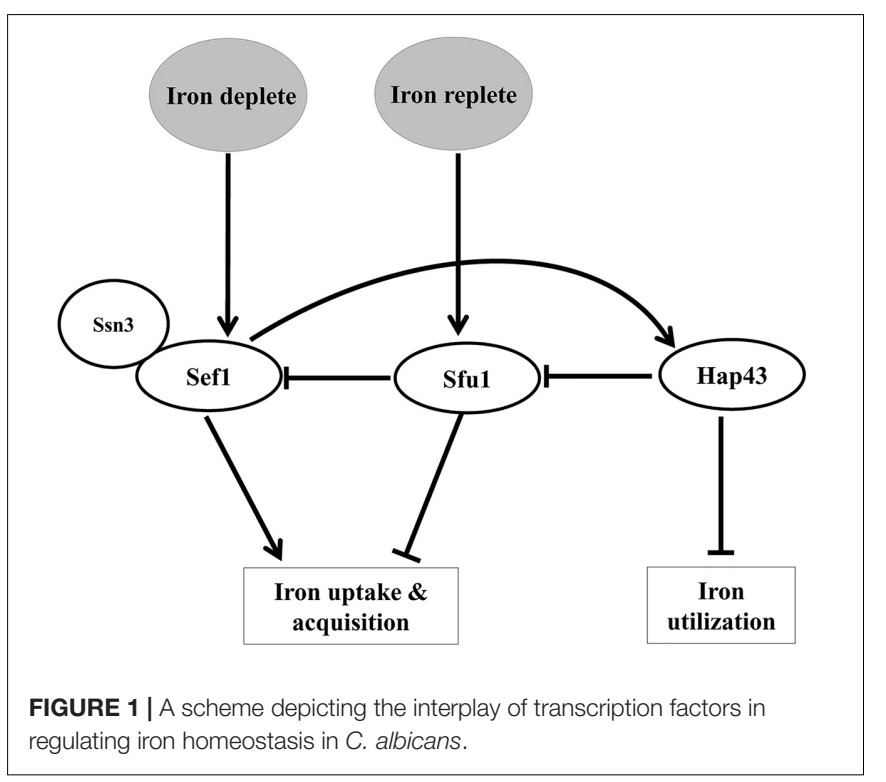

exhibit increases in mitochondrial iron and expression of iron regulon genes in iron sufficient conditions; a situation that otherwise is the signature of iron starved cells (Yamaguchi-Iwai et al., 1996; Kispal et al., 1999; Foury and Talibi, 2001; Bellí et al., 2004; Hausmann et al., 2008; Patil et al., 2013). Likewise, in C. albicans, the loss of SSQ1 and MGE1, proteins involved in $\mathrm{Fe}-\mathrm{S}$ cluster biogenesis leads to phenotypes similar to $S$. cerevisiae Fe-S cluster mutants (Demuyser et al., 2017; Dong et al., 2017). Considering that mitochondria serves as a site for the biogenesis of $\mathrm{Fe}-\mathrm{S}$ clusters in eukaryotes, impairment in mitochondrial activity not only perturbs $\mathrm{Fe}-\mathrm{S}$ cluster machinery but also results in the activation of the $S$. cerevisiae Aft1 and the iron regulon in iron-sufficient conditions (Chen et al., 2004; Patil et al., 2013). As disruption in $\mathrm{Fe}-\mathrm{S}$ cluster synthesis is not associated with lowered cytosolic iron levels, Aft1 activation is suggested to be dependent on a product of the mitochondrial $\mathrm{Fe}-\mathrm{S}$ biogenesis pathway rather than on cytosolic iron pools (Rutherford et al., 2005). Concordantly, compromising mitochondrial function, by deleting FZO1, in C. albicans also results in constitutive expression of the Sef1-regulated iron regulon in iron-replete conditions (Thomas et al., 2013).

In our previous study, we demonstrated that loss of FZO1 affects mitochondrial morphology resulting in loss of mtDNA and perturbation of the mitochondrial membrane potential; thus generating cells with dysfunctional/defective mitochondria. FZO1, a GTPase and a component of the mitochondrial fusion machinery, is known to facilitate the biogenesis of mitochondria in yeast (Hermann et al., 1998; Rappaport et al., 1998; Mozdy and Shaw, 2003). Additionally, fzol $\Delta / \Delta$ cells exhibit increased susceptibility to azole antifungals and oxidants as well as altered ergosterol and phospholipid levels. A network model, based on the transcriptional analysis of the $f z 01 \Delta / \Delta$ cells, showed three distinct co-regulated gene clusters that are associated with specific biological processes, out of which the most striking subset of genes was the one that contained genes involved in iron homeostasis. Given the phenotypic overlap with respect to the altered expression of iron regulon between the mutants of the $\mathrm{Fe}-\mathrm{S}$ cluster pathway and mitochondria, we posit a link between mitochondrial-dependent $\mathrm{Fe}-\mathrm{S}$ cluster biogenesis and iron homeostasis in C. albicans. Although the significance of $\mathrm{Fe}-\mathrm{S}$ cluster synthesis pathway in maintaining mitochondrial functions and iron homeostasis in C. albicans has been addressed (Dong et al., 2017), the question whether perturbations in the synthesis of $\mathrm{Fe}-\mathrm{S}$ clusters are transduced to Sef1 for activating the iron regulon remain unanswered in this pathogenic fungus.

To systematically explore the importance of $\mathrm{Fe}-\mathrm{S}$ cluster biogenesis for cellular iron homeostasis in $\mathrm{fzol} \Delta / \Delta$ cells, we sought to evaluate the mitochondrial iron content and the activity of a Fe-S cluster containing-protein, aconitase. We report that aconitase activity is compromised in $f z o 1 \Delta / \Delta$ cells and forced overexpression of key components (ISU1, NFS1, and YFH1) of the $\mathrm{Fe}-\mathrm{S}$ biogenesis pathway in the mutant partially restore the activity of this enzyme. Sef1 activation and its retention in the nucleus underlies the increase in expression of the iron regulon in $f z o 1 \Delta / \Delta$ cells, as the repression of this regulator is impaired in iron-replete conditions possibly due to lack of a functional $\mathrm{Fe}-\mathrm{S}$ cluster biogenesis pathway. Thus, dysfunctional mitochondria 
not only perturb Fe-S cluster biogenesis but also affect the ability of Sef1 to sense the pools of cellular iron for regulating iron metabolism. Herein, we propose that iron sensing by Sef1 is linked to a signal that emanates from functional mitochondria in the form of $\mathrm{Fe}-\mathrm{S}$ clusters. Collectively these data uncover a new regulatory pathway connecting the iron-dependent regulation of Sef1 activity to mitochondria-dependent $\mathrm{Fe}-\mathrm{S}$ synthesis in C. albicans.

\section{MATERIALS AND METHODS}

\section{Media}

The strains (Supplementary Table S1) were maintained as frozen stocks and propagated at $30^{\circ} \mathrm{C}$ on the following media. YEPD (yeast extract peptone dextrose; $10 \mathrm{mg} / \mathrm{mL}$ yeast extract, $20 \mathrm{mg} / \mathrm{mL}$ peptone, $20 \mathrm{mg} / \mathrm{mL}$ glucose, and $25 \mathrm{mg} / \mathrm{mL}$ agar) liquid medium and agar plates containing $200 \mu \mathrm{g} / \mathrm{mL}$ of nourseothricin (Werner Bioreagents) were used for selection of deletion mutants and nourseothricin resistant strains. To obtain nourseothricin sensitive derivatives of transformants, strains were grown in YPM (yeast extract peptone maltose; $10 \mathrm{mg} / \mathrm{mL}$ yeast extract, $20 \mathrm{mg} / \mathrm{mL}$ peptone, and $20 \mathrm{mg} / \mathrm{mL}$ maltose) for $8 \mathrm{~h}$ and plated on $25 \mu \mathrm{g} / \mathrm{mL}$ nourseothricin. C. albicans strains were routinely propagated in YEPD, also referred to as "iron-replete" medium. "Iron-depleted" medium is YEPD supplemented with one of the specific iron chelators, bathophenanthroline disulfonic acid (BPS). The following supplements, BPS (Sigma), Zymolase-20T (MP Biomedicals), Poly-L-lysine (Sigma), DAPI (4,6-diamidino-2-phenylindole, Molecular Probes/Invitrogen) were added to the media/buffer at concentrations described.

\section{In vitro Growth Assays}

Strains grown overnight in YEPD plate were diluted in $9 \mathrm{mg} / \mathrm{mL}$ saline solution to $\mathrm{OD}_{600}=0.7$. Then, $5 \mu \mathrm{L}$ portions of four dilutions $\left(5 \times 10^{3}-5 \times 10^{5}\right.$ cells $)$ were spotted onto YEPD plates containing iron chelator, $500 \mu \mathrm{M}$ BPS and BPS with added $100 \mu \mathrm{M} \mathrm{FeCl}_{3}$. Plates were photographed after $72 \mathrm{~h}$ at $30^{\circ} \mathrm{C}$.

\section{Strain Construction}

\section{Construction of Deletion Cassettes for FZO1}

Candida albicans mutants and complemented strains were created by standard two-step disruptions by using SAT1-flipper strategy as described (Thomas et al., 2013). Both alleles of FZO1 were deleted in sef1 $\Delta / \Delta$ strain (Noble et al., 2010). Strains and plasmids used in the study are listed in Supplementary Tables S1, S2.

\section{C-Terminal Myc Tagging}

Myc-tagged allele of Sef1 (accession number XM_708348) (van het Hoog et al., 2007) was constructed by using pADH34 vector which contains a $13 \mathrm{X}$ Myc epitope tag preceding the SAT1-flipper cassette as previously described (Nobile et al., 2009). Primers used for amplification of cassette and detection for integration is listed in Supplementary Table S3. The polymerase chain reaction (PCR) amplicon obtained with primers SEF1mycFnostop and SEF1mycRUTR constitutes a 13X Myc epitope tag, SAT1-flipper cassette, 65-bp region homologous to SEF1 ORF minus its stop codon on the $5^{\prime}$ end of the Myc tag and a 65-bp region homologous to SEF1 UTR downstream of the stop codon on the $3^{\prime}$ end of the SAT1-flipper cassette (Gillum et al., 1984). This PCR product was transformed into SC5314 (wild type) and $f z o 1 \Delta / \Delta$. Correct integration of the C-terminal 13X Myc epitope tag and SAT1-flipper was verified by PCR using detection primers pairs SEF1upstreamcheckF and AHO300, SEF1downstreamcheckR and AHO301. The primer pairs SEF1downstreamcheckR and AHO302 were used to confirm the flipping out of the SAT1-flipper cassette. The $13 \mathrm{X}$ Myc epitope tag and the region of homology to the $3^{\prime}$ end of SEF1 used for integration of the SAT1-flipper cassette was confirmed by sequencing the PCR product generated using primers SEF1upstreamcheckF and AHO283.

\section{Overexpressor Strain Construction}

(i) The C. albicans strains overexpressing YFH1 (accession number XM_706449), NFS1 (accession number XM_715279), and ISU1 (accession number XM_716291) (Muzzey et al., 2013; Supplementary Table S1) were constructed using plasmid pCJN542 (Nobile et al., 2008). Primers amplify the Ashbya gossypii TEF1 promoter, the C. albicans NAT1 ORF, the A. gossypii TEF1 terminator and C. albicans TDH3 promoter with $100 \mathrm{bp}$ of hanging homology to promoter region and $100 \mathrm{bp}$ of hanging homology within the ORF from initiation codon of YFH1, NFS1, and ISU1 (Supplementary Table S3). The transformation into wild type and $f z 01 \Delta / \Delta$ was done as described earlier and nourseothricin positive transformants were screened using detection primers listed in Supplementary Table S3. (ii) The SFU1 overexpression strain in wild type (SN95) and $f z o 1 \Delta / \Delta$ was created by using plasmid pSN141 as described by Chen and Noble (2012). pSN141 was engineered to contain (59-39): a PmeI site; 350-450 bp of sequence upstream of the C. albicans LEU2 ORF; the C. dubliniensis ARG4 gene (selectable marker); the TDH3 promoter; the SFU1 (accession number XM_718460) (Muzzey et al., 2013) ORF; 350-450 bp sequence downstream of the LEU2 ORF; and a second PmeI restriction site. After digestion with PmeI, the plasmid was transformed into the strain SN95, generating SLP23 (Noble and Johnson, 2005). Correct integration of the insert in $\mathrm{Arg}^{+}$ transformants was verified by PCR, and overexpression of SFU1 was confirmed by qPCR. FZO1 gene was deleted in strain SLP23 by SAT1-flipper strategy and deletion was confirmed by Southern hybridization.

\section{Protein Extracts and Immunoblot Analysis}

Candida albicans was grown at $30^{\circ} \mathrm{C}$ with starting $\mathrm{OD}_{600}$ of 0.4 and cells were harvested when $\mathrm{OD}_{600}$ reached 2.0. Culture was pelleted down $\left(10,000 \mathrm{rpm} ; 4^{\circ} \mathrm{C}\right)$, washed with $1 \mathrm{X}$ PBS once and resuspended in $200 \mu \mathrm{L}$ ice cold lysis buffer $(50 \mathrm{mM}$ Tris$\mathrm{HCl} \mathrm{pH}$ 7.5, $150 \mathrm{mM} \mathrm{NaCl}, 1 \mathrm{mM}$ EDTA, 1\% Triton 100X), $5 \mu \mathrm{L}$ protease inhibitor cocktail, $10 \mu \mathrm{L}$ phenylmethylsulfonyl fluoride (PMSF, 0.1 M stock) and $200 \mu \mathrm{L}$ glass beads. Breaking was done for $1 \mathrm{~min}$ on cell breaker with intermittent chilling 
on ice three times, followed by centrifuging at $13,000 \mathrm{rpm}$ to obtain a clear lysate, which was transferred into fresh tube. Total protein was determined using Bio-Basic BCA assay kit according to manufacturer's instructions, and $100 \mu \mathrm{g}$ of total protein was fractionated by SDS-PAGE using 10\% Mini-Protean TGX gels (Bio-Rad). Fractionated proteins were transferred to nitrocellulose/PVDF membranes and blocked with $50 \mathrm{mg} / \mathrm{mL}$ BSA (in 1X PBS) for $2 \mathrm{~h}$ at room temperature. Membrane was incubated with 9B11 c-Myc primary antibody for overnight (Cell Signaling Technology) and then Horseradish peroxidase (HRP)-conjugated secondary antibody for $2 \mathrm{~h}$ (Bio-Rad). Blots were visualized with the ECL Plus Western blotting detection system (Biorad).

\section{Quantitative Real-Time PCR}

Candida albicans strains were grown overnight in YEPD, sub-cultured from a starting $\mathrm{OD}_{600}$ of 0.3 in fresh YEPD and incubated at $30^{\circ} \mathrm{C}$ for $4 \mathrm{~h}$. Total RNA, isolated using the RNeasy Mini Kit (Qiagen), was treated with DNase I (Fermentas Life Sciences) to remove contaminating DNA. cDNA was synthesized with a RevertAid H Minus First Strand cDNA synthesis kit (Fermentas Life Sciences) according to the manufacturer's protocol. Real-time PCRs were performed in a volume of $25 \mu \mathrm{L}$ using the Thermo Scientific Maxima SYBR green mix in a 96-well plate. For the relative quantification of gene expression, the comparative threshold cycle $\left(C_{\mathrm{T}}\right)$ method was used, where the fold change was determined as $2^{-\triangle \Delta C T}$. ACT1 (accession number XM_019475182) (van het Hoog et al., 2007) was used as the internal control and the transcript level of the gene of interest was normalized to the ACT1 (actin) levels.

\section{Immunofluorescence}

Briefly, C. albicans strains carrying Sef1-Myc were grown at $30^{\circ} \mathrm{C}$ up to $\mathrm{OD}_{600}=1.0$, in "iron-replete" (YEPD, $1.23 \mu \mathrm{M}$ basal $\mathrm{Fe}^{3+}$ concentration) and "iron-depleted" medium (YEPD supplemented with $500 \mu \mathrm{M}$ BPS). As described by Inglis and Johnson (2002), cells were fixed with 4.5\% formaldehyde for $1 \mathrm{~h}$ at room temperature and cell wall digestion was carried out with zymolase $(1 \mathrm{mg} / \mathrm{mL})$ for $30 \mathrm{~min}$ at $37^{\circ} \mathrm{C}$ with gentle shaking in total $500 \mu \mathrm{L}$ SP $(1.2 \mathrm{M}$ sorbitol, $0.1 \mathrm{M}$ potassium phosphate) buffer. Antibody hybridization were performed, 9B11 anti-c-Myc antibody (Mouse, Cell Signaling Technology) was used at a 1:300 dilution and detected with a 1:400 dilution of Cy2-conjugated secondary antibody (Jackson ImmunoResearch, 715-225-151). To visualize cell nuclei, cells were stained with $1 \mu \mathrm{g} / \mathrm{mL}$ DAPI (DAPI channel color was changed from blue to red). Slides were mounted with Fluoromount-G (Southern Biotechnology Associates, Inc.) and images were captured using 100X oil objective.

\section{Aconitase Activity Assay and Iron Estimation \\ Mitochondria Isolation}

(i) Preparation of crude mitochondria. Cells were grown overnight and sub-cultured in $250 \mathrm{~mL}$ of YEPD broth overnight at $30^{\circ} \mathrm{C}$ with starting $\mathrm{OD}_{600}$ of 0.1 . Cells were harvested at $5000 \mathrm{rpm}$ for $10 \mathrm{~min}$, washed one time each with $50 \mathrm{~mL}$ cold water and buffer A $(50 \mathrm{~mL}, 1 \mathrm{M}$ sorbitol, $10 \mathrm{mM} \mathrm{MgCl} 2,50 \mathrm{mM}$ Tris$\mathrm{HCl}, \mathrm{pH}$ 7.8) supplemented with $30 \mathrm{mM}$ dithiothreitol (DTT). As described by Li et al. (2011), $3 \mathrm{~g}$ of cells were suspended in buffer $\mathrm{A}$ for $15 \mathrm{~min}$ at room temperature with shaking (100 rpm), then collected and suspended in $15 \mathrm{~mL}$ of buffer A with $1 \mathrm{mM}$ DTT containing $100 \mathrm{mg}$ Zymolase 20T (Seikagaku Biobusiness, Inc.) per $15 \mathrm{~g}$ of pelleted cells. Cultures were kept for shaking $(100 \mathrm{rpm})$ at $30^{\circ} \mathrm{C}$ for $60 \mathrm{~min}$ or until $90 \%$ of cells was converted into spheroplasts (as checked by light microscopy). Digestion was stopped by adding $15 \mathrm{~mL}$ of ice-cold buffer A and spheroplasts were washed twice with buffer A. Spheroplasts were suspended in $10 \mathrm{ml}$ of cold buffer $\mathrm{B}(0.6 \mathrm{M}$ mannitol, $1 \mathrm{mM}$ EDTA, $5 \mathrm{mg} / \mathrm{mL}$ BSA, $1 \mathrm{mM}$ PMSF, and $10 \mathrm{mM}$ Tris-Cl, pH 7.4) and were broken mechanically using a Dounce homogenizer on an ice bath (15 times). Cell debris was removed by low speed centrifugation (1000 rpm for $10 \mathrm{~min}$ ) in $15 \mathrm{~mL}$ falcon (chilled). The supernatant containing mitochondria was centrifuged at $10,000 \mathrm{rpm}$ for $10 \mathrm{~min}$ and the pellet was washed twice with $10 \mathrm{~mL}$ of ice cold buffer C $(0.6 \mathrm{M}$ mannitol, $1 \mathrm{mM}$ EDTA, $10 \mathrm{mg} / \mathrm{mL}$ BSA, $10 \mathrm{mM}$ Tris- $\mathrm{HCl}, \mathrm{pH} \mathrm{7.0)}$ in $15 \mathrm{~mL}$ falcon (chilled). Mitochondria were suspended in $500 \mu \mathrm{L}$ of buffer D (0.6 M mannitol, $10 \mathrm{mM}$ Tris- $\mathrm{HCl}, \mathrm{pH}$ 7.0). (ii) Purification of mitochondria. Mitochondria purification was performed using a two-step gradient, $2 \mathrm{~mL}$ PB1 buffer containing 30\% (v/v) Percoll TM was placed at the bottom of a centrifugation tube (Beckman, Inc) (PB1: $0.3 \mathrm{M}$ mannitol, $10 \mathrm{mM}$ TES, $1 \mathrm{mg} / \mathrm{mL}$ BSA. pH 7.5). Then, $2 \mathrm{~mL}$ of PB2 buffer containing 20\% Percoll $(\mathrm{v} / \mathrm{v})$ was layered on the top of PB1 (PB2: $0.3 \mathrm{M}$ sucrose, $10 \mathrm{mM}$ TES, $1 \mathrm{mg} / \mathrm{mL}$ BSA, $\mathrm{pH}$ 7.5). The crude mitochondria preparation was layered on the top of the gradient which was then centrifuged at $40,000 \times \mathrm{g}$ for $45 \mathrm{~min}$ at $4^{\circ} \mathrm{C}$. A whitish band (purified mitochondria) was collected from the interface of the Percoll gradient. Purified mitochondria were washed twice by centrifugation in $3 \mathrm{~mL}$ of PB1 buffer for $10 \mathrm{~min}$ at $3000 \mathrm{rpm}$ (15 mL falcon).

\section{Aconitase Activity Assay}

Mitochondria were quantified using BCA protein assay kit (Bio Basic). Enzymatic activity of the mitochondrial Fe-S protein aconitase was measured as described earlier (Pierik et al., 2009). $950 \mu \mathrm{L}$ of aconitase buffer was added to a quartz cuvette. Mitochondria were dissolved $(50 \mu \mathrm{g})$ in $60 \mu \mathrm{L}$ of mitochondria lysis buffer (MLB), mixed properly. Fifty microliters of this lysed mitochondria was added in quartz cuvette mixed well and absorbance was measured at $235 \mathrm{~nm}$ for $2 \mathrm{~min}$. $\Delta \varepsilon_{235} \mathrm{~nm}=4950 / \mathrm{M} \mathrm{cm}$.

\section{Iron Estimation}

Purified mitochondria (100 $\mu \mathrm{g}$ of mitochondrial protein) were digested in $70 \% \mathrm{HNO}_{3}$ by boiling for 2 min and then diluted to $30 \% \mathrm{HNO}_{3}$. Iron content was determined using an inductively coupled plasma-mass spectrometry (ICP-MS). 


\section{RESULTS}

\section{Dysfunctional Mitochondria Results in Mitochondrial Iron Accumulation}

The constitutive high expression of the iron-regulon genes in $f z o 1 \Delta / \Delta$ cells (Supplementary Table S4) even in ironreplete conditions (Thomas et al., 2013), is reminiscent of transcriptional changes observed during iron starvation and indicates toward the possibility of perturbed iron homeostasis in the mutant. We presumed that the constitutive expression of iron regulon genes in $f z o 1 \Delta / \Delta$ cells might result in elevated iron levels in the mitochondria. To this end, we measured mitochondrial iron levels using ICP-MS in $f z o 1 \Delta / \Delta$ cells. We show that mitochondrial iron levels in the $f z 01 \Delta / \Delta$ mutant were significantly increased by $77 \%$ relative to the wild type (Figure 2A). We expected that the induced expression of plasma membrane localized iron uptake system (FET34) and the mitochondrion membrane localized iron importer (MRS4) of the iron regulon might be supporting iron acquisition in $f z o 1 \Delta / \Delta$ cells. In line with this, fzo1 $\Delta / \Delta$ cells exhibited twofold increase in the transcript level of FET34 and MRS4 (Figure 2B), supporting the accumulation of iron within the mitochondria. Altogether, this set of data suggests that, dysfunctional mitochondria may be the basis of mitochondrial iron overload and increase in expression of the iron regulon; indicators for perturbed iron homeostasis in $f z 01 \Delta / \Delta$ cells.

\section{fzo1 $\Delta / \Delta$ Displays Deficiencies in Fe-S Cluster Biogenesis}

Given that the activation of the iron regulon genes is dependent on the utilization of mitochondrial iron for the synthesis of $\mathrm{Fe}-\mathrm{S}$ clusters (Garland et al., 1999; Chen et al., 2002; Hausmann et al., 2008), we reasoned that perturbed $\mathrm{Fe}-\mathrm{S}$ cluster biogenesis in defective mitochondria may be the basis of iron homeostasis defect in $f z 01 \Delta / \Delta$ cells. To assess this, we measured the activity of the $4 \mathrm{Fe}-4 \mathrm{~S}$ containing mitochondrial enzyme aconitase from purified mitochondrial extracts of wild-type, $f z o 1 \Delta / \Delta$ and FZO1 revertant strains grown in standard conditions. Aconitase activity in $f z o 1 \Delta / \Delta$ cells was significantly decreased by $70 \%$ relative to wild type, whereas the activity of this enzyme was restored to wild type levels (80\%) in the revertant strain (Figure 3A and Supplementary Table S5).

Furthermore, if absence of FZO1 decreases aconitase activity because of defect in $\mathrm{Fe}-\mathrm{S}$ biogenesis, then we assumed that overexpression of proteins involved in this process may compensate for (i) the decreased aconitase activity and (ii) the increased expression of iron regulon genes, in the mutant. The central components of the mitochondria-localized $\mathrm{Fe}-\mathrm{S}$ cluster machinery include cysteine desulphurase (Nfs1), iron-chaperone (Yfh1), and Isu1/2 that serves as scaffold for de novo synthesis of Fe-S cluster (Lill et al., 2012). Hence, we created strains in which the endogenous promoter of YFH1, NFS1, and ISU1 genes was replaced by the constitutively active $T D H 3$ promoter in wild type and $f z o 1 \Delta / \Delta$ cells. We validated the expression of the transcripts of the selected genes in all the overexpressing strains (data not shown). Thereafter, aconitase activity was measured in wild
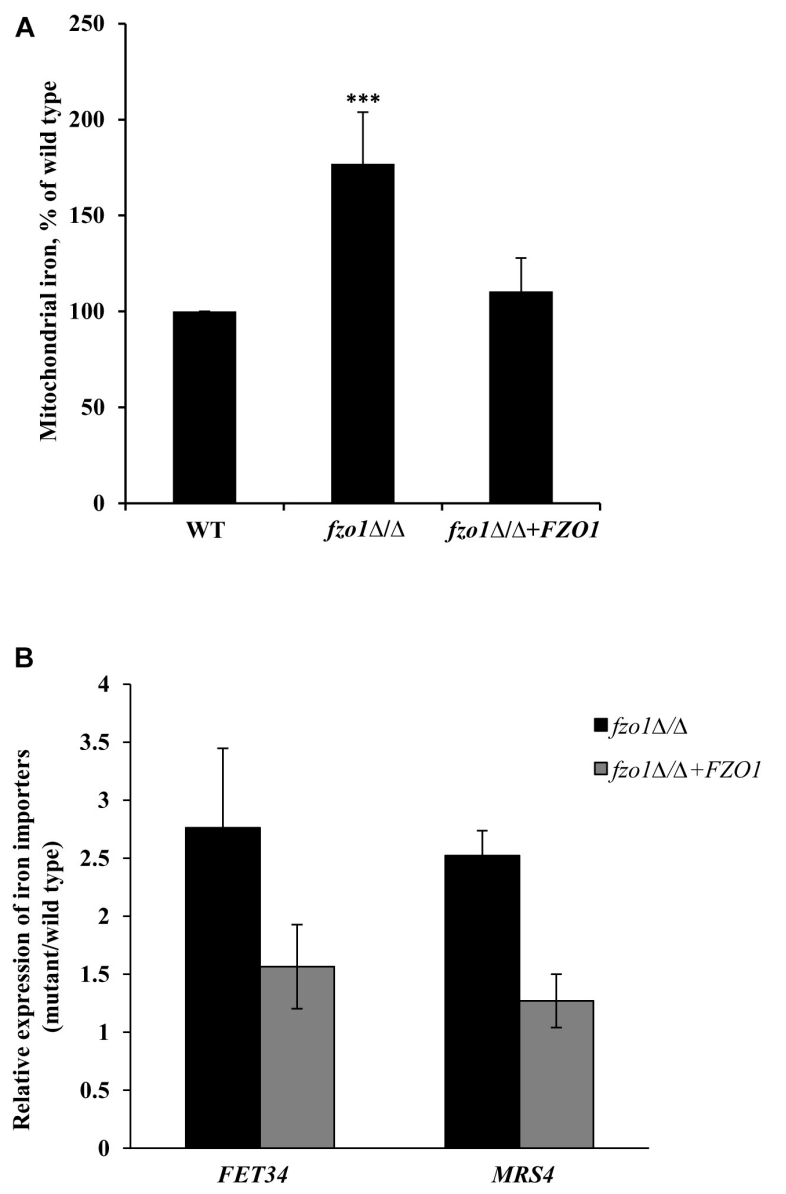

FIGURE 2 | Dysfunctional mitochondria results in mitochondrial iron accumulation. (A) Mitochondrial iron overload in $\mathrm{fzo} 1 \Delta / \Delta$. Cells were grown in YEPD at $30^{\circ} \mathrm{C}$ to the logarithmic phase and mitochondrial iron levels were determined by inductively coupled plasma-mass spectrometer. Data shown are mean $\pm \operatorname{SD}(n=9)$. (B) High expression of FET34 and MRS4 in $f z 01 \Delta / \Delta$. The mRNA level of FET34 and MRS4 was quantified by qPCR in $\mathrm{fzO} 1 \Delta / \Delta$ relative to wild type. The asterisk indicates a significant difference relative to wild type, the two-tailed, unpaired $t$-test was used to determine the statistical relevance. ${ }^{* * *} P<0.001$.

type and $f z o 1 \Delta / \Delta$ cells overexpressing YFH1, NFS1, and ISU1 $\left(\mathrm{YFH1}_{1} \mathrm{\textrm {OE }}, \mathrm{NFS}_{1}{ }^{\mathrm{OE}}\right.$, and $I S U 1^{\mathrm{OE}}$ ) (Supplementary Table S5). WT$\mathrm{YFH1}^{\mathrm{OE}}, \mathrm{WT}-\mathrm{NFS} 1^{\mathrm{OE}}$, and WT-ISU1 ${ }^{\mathrm{OE}}$ resulted in a 12,13 , and $21 \%$ increase in aconitase activity, respectively, compared to wild type (Figure 3B). Interestingly, the overexpressing strain $f z o 1 \Delta / \Delta$-ISU1 ${ }^{\mathrm{OE}}$ exhibited $44 \%$ increase while $f z o 1 \Delta / \Delta$ $Y F H 1^{\mathrm{OE}}$ and $f z 01 \Delta / \triangle-N F S 1^{\mathrm{OE}}$ showed 18 and $21 \%$ increase in aconitase activity, respectively, compared to their parent strain (Figure 3B). This result suggests that the activity of aconitase, a Fe-S enzyme is affected in cells with dysfunctional mitochondria and that forced overexpression of genes involved in $\mathrm{Fe}-\mathrm{S}$ biogenesis is able to partially compensate for the loss of aconitase activity in the $f z o 1 \Delta / \Delta$ cells.

Next, we determined the expression levels of CCC2, FRE2, FRE31, and RBT5 (iron regulon genes) in two independent clones of $f z 01 \Delta / \Delta-I S U 1{ }^{\mathrm{OE}}$. We show that the expression level of the iron 


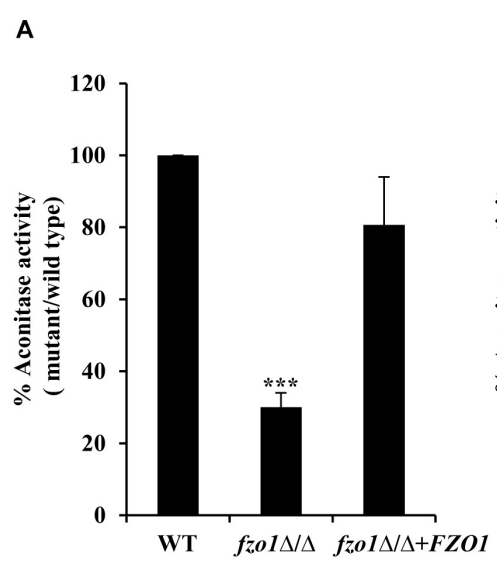

\section{B}
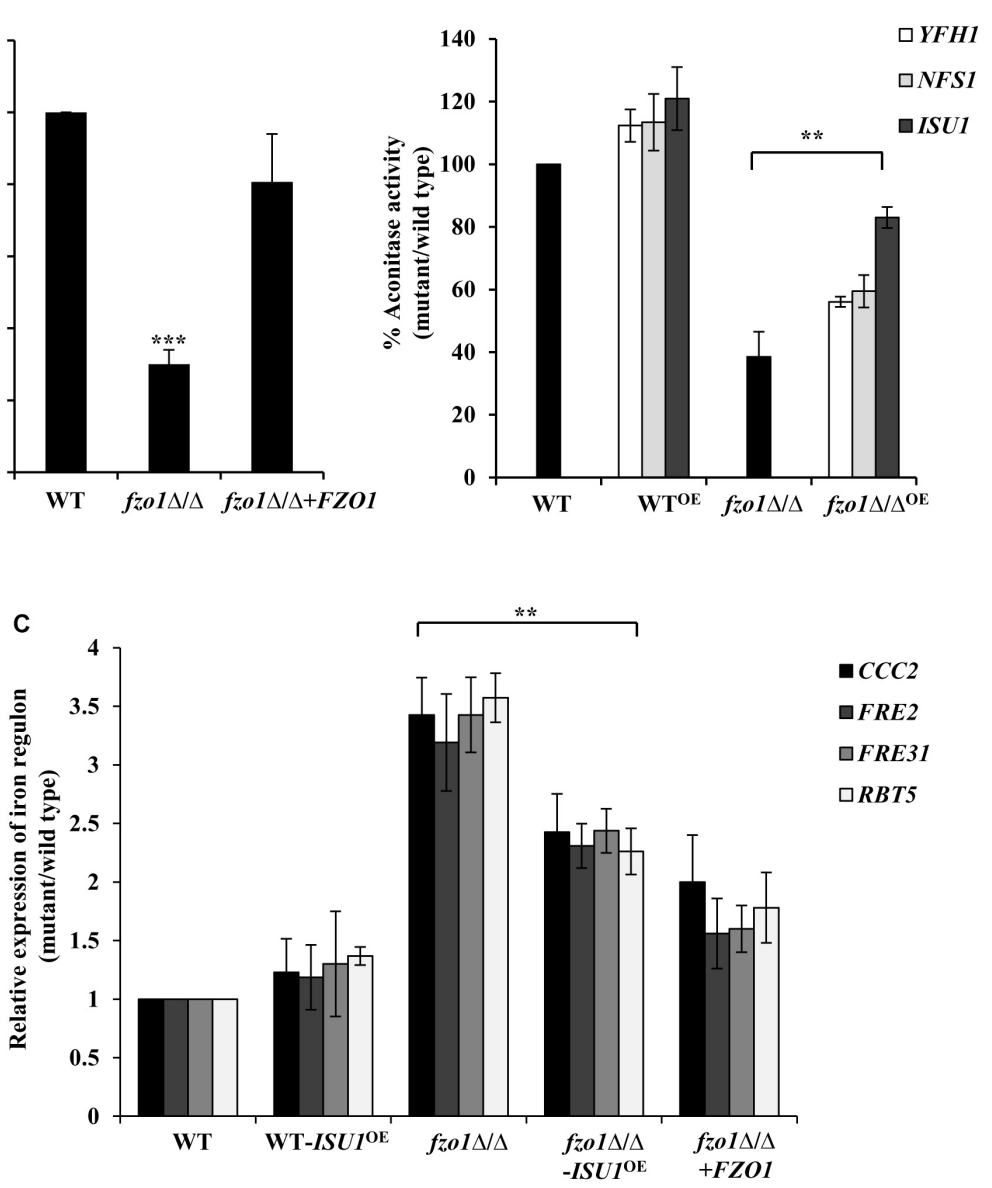

$\square C C C 2$

$\square F R E 2$

$\square$ FRE31

$\square R B T 5$

FIGURE $3 \mid f z 01 \Delta / \Delta$ displays deficiencies in Fe-S cluster biogenesis. (A) Decreased mitochondrial aconitase activity in $f z 01 \Delta / \Delta$. Cells were grown in YEPD medium at $30^{\circ} \mathrm{C}$ and activity was assayed from purified mitochondria. Values are mean $\pm \mathrm{SD}(n=3)$. (B) Rescued aconitase activity in fzo1 $\Delta / \Delta$-overexpressing strains of Fe-S biogenesis genes. WTOE and fzo1 $\Delta / \Delta \mathrm{OE}$ are strains with overexpressing genes $Y F H 1, N F S 1$, and ISU1. \% Aconitase activity is calculated relative to wild type in panels (A) and (B). (C) Overexpression of ISU1 in $\mathrm{fZO} 1 \Delta / \Delta$ cells partially rescue upregulated expression of iron regulon genes. Indicated strains were grown in YEPD to logarithmic phase at $30^{\circ} \mathrm{C}$ and $\mathrm{mRNA}$ levels of indicated genes was quantified by qPCR. Relative transcript level was calculated by $2^{-} \Delta \triangle C T$, normalized to ACT1 (endogenous control). Values are mean $\pm \mathrm{SD}(n=3)$ and are derived from three independent RNA preparations. The asterisk indicates a significant difference relative to $\mathrm{fzo} 1 \Delta / \Delta$ in panels $\mathbf{( B )}$ and $(\mathbf{C})$. Two-tailed, unpaired $t$-test was used to determine the statistical relevance. ${ }^{* *} P<0.01 ; * * * P<0.001$.

regulon genes in the $f z o 1 \Delta / \Delta-I S U 1{ }^{\mathrm{OE}}$ strain was reduced similar to the reconstituted strain (ranged between 1.5 and 2.4-fold) when compared to $f z o 1 \Delta / \Delta$ cells (Figure 3C), suggestive of partial repression of iron regulon upon forced overexpression of ISU1. Therefore, we surmise that insufficient mitochondrial activity results in defects in $\mathrm{Fe}-\mathrm{S}$ synthesis, which in turn causes the induction of the iron regulon in C. albicans. Together, these results forge a link between the induction of iron regulon and mitochondrial Fe-S cluster synthesis in C. albicans.

\section{Induction of SEF1 Is the Basis of Activated Iron Regulon in fzo1 $\Delta / \Delta$}

Transcriptome analysis of $f z 01 \Delta / \Delta$ cells in iron-replete condition showed a total of 27 differentially regulated genes that are annotated as genes involved in iron homeostasis in Candida genome database (CGD; Thomas et al., 2013). Out of the
27 genes, 16 genes are shown to be regulated by the transcription factors, Sef1, Sfu1, and Hap43 in C. albicans (Supplementary Table S4), pointing to the involvement of these transcription factors in regulating iron homeostasis in the mutant. As most of the Sef1-controlled iron regulon genes were upregulated, we evaluated the expression of this regulator in fzol $\Delta / \Delta$ cells. qPCR analysis performed in iron-replete condition confirmed significantly higher transcript levels of SEF1 (2.5-fold) with no significant change in SFU1 expression in the fzo1 $\Delta / \Delta$ cells, compared to wild type (Figure 4A). Furthermore, we argued that if the induced expression of SEF1 requires the synthesis of the mitochondrial Fe-S cluster, then overexpressing ISU1 in the fzol $\Delta / \Delta$ cells should repress the transcript levels of this regulator; an outcome of rescuing defective Fe-S cluster synthesis. Concordantly, we observed a 1.2 -fold reduction in $S E F 1$ expression in $f z o 1 \Delta / \Delta-I S U 1{ }^{\mathrm{OE}}$, compared to the parent strain, affirming our proposition (Figure 4B). 

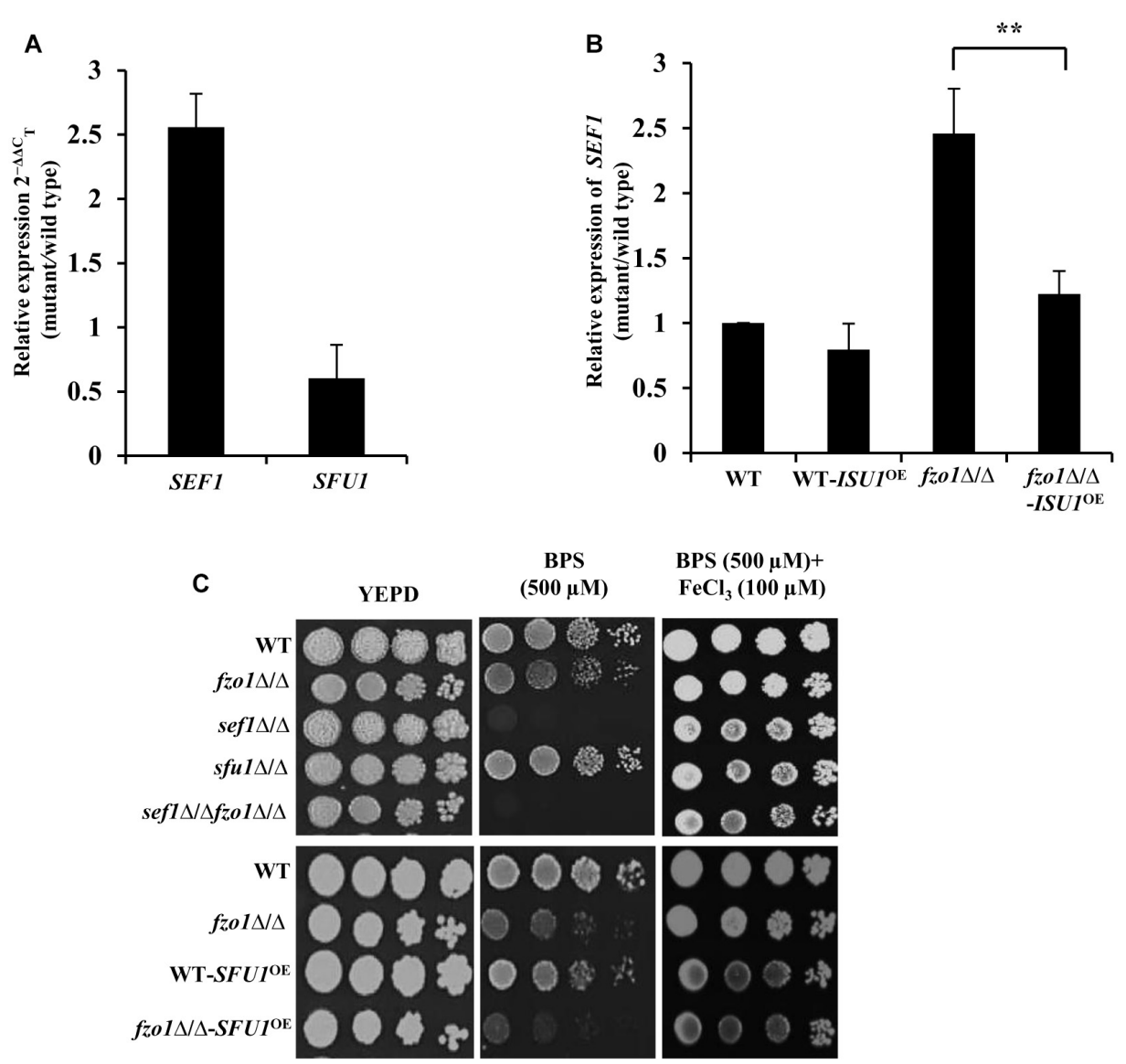

FIGURE $4 \mid$ Induction of SEF1 is the basis of activated iron regulon in $f z 01 \Delta / \Delta$ cells. (A) High expression of $S E F 1$ in $f z 01 \Delta / \Delta$ in iron replete condition. The $m R N A$ level of SEF1 and SFU1 was quantified by qPCR in $f z 01 \Delta / \Delta$ relative to wild type. (B) Partial restoration of $S E F 1$ in $f z O 1 \Delta / \Delta-I S U 1 O E$ strain. qPCR-based expression analysis SEF1 was done in fzo1 $\Delta / \Delta$ and $\mathrm{fZO}_{1} \Delta / \Delta-I S U 1 \mathrm{OE}$. In panel (A) and (B) strains were grown in iron-replete medium and expression was normalized to internal control ACT1. Values are reported as fold change in expression over wild type. Data shown are mean \pm SD $(n=3)$. The asterisk indicates a significant difference relative to $f z 01 \Delta / \Delta$. A two-tailed, unpaired $t$-test was used to determine the statistical relevance. ${ }^{* *} P<0.01$. (C) For phenotypic comparison $C$. albicans strains were spotted on iron-replete (standard), iron-deplete (with iron chelators, BPS) and iron-supplemented medium (FeCl 3 added in low-iron condition). Fivefold dilution were made and $5 \mu \mathrm{L}$ of each dilution series was applied to solid test media, followed by incubation at $30^{\circ} \mathrm{C}$ for $72 \mathrm{~h}$.

The $f z 01 \Delta / \Delta$ mutant exhibited wild type susceptibility in iron-deplete medium (YEPD+BPS) (Figure 4C). We show that deletion of FZO1 in sef1 $\Delta / \Delta$ background abrogated the growth of sef $1 \Delta / \Delta f z 01 \Delta / \Delta$ cells in iron-deplete medium, compared to the parent strains (Figure 4C), suggesting that Sef1, in compliance with its role in wild type cells (Chen et al., 2011) also facilitates adaptation of cells with dysfunctional mitochondria to low iron stress. The specificity of the Sef1-dependent phenotype in iron-deplete medium was confirmed in $f z o 1 \Delta / \Delta$ cells by (i) addition of $\mathrm{FeCl}_{3}$ to the BPS-treated medium and (ii) overexpressing Sful in wild type and $f z 01 \Delta / \Delta$ cells. The growth defect of $\operatorname{sef} 1 \Delta / \Delta$ and $\operatorname{sef} 1 \Delta / \Delta f z o 1 \Delta / \Delta$ was reversed by $\mathrm{FeCl}_{3}$ addition to iron-deplete medium (Figure 4C). Next, we tested the ability of the WT-SFU1 ${ }^{\mathrm{OE}}$ and $f z 01 \Delta / \triangle-S F U 1^{\mathrm{OE}}$ cells to adapt to low iron stress. Increased transcript level of SFU1 was confirmed by qPCR in WT-SFU1 ${ }^{\mathrm{OE}}$ and $f z 01 \Delta / \Delta-S F U 1^{\mathrm{OE}}$ cells (data not shown). In wild type cells, forced overexpression of SFU1 (WT-SFU1 ${ }^{\mathrm{OE}}$ ) does not affect SEF1 mRNA levels but leads to a decrease in Sef1 protein levels, suggesting a posttranscriptional role of Sfu1 in regulating Sef1 function. The SFU1 overexpressing strain thus renders cells unable to tolerate low iron stress (Chen and Noble, 2012). Consistently, WT-SFU1 ${ }^{\text {OE }}$ in this study also showed increased susceptibility to low iron stress condition, compared to the wild type (Figure 4C). We hypothesized that if Sef1 and Sfu1 interplay exists also in cells with dysfunctional mitochondria, then overexpressing SFU1 in $f z o 1 \Delta / \Delta$ should inhibit Sef1 activity resulting in diminished growth of the mutant in iron-deplete medium. In iron-deplete medium, the $f z o 1 \Delta / \Delta-S F U 1^{\mathrm{OE}}$ strain showed a substantial growth defect compared to $f z o 1 \Delta / \Delta$ cells, suggestive of the inhibitory effect of Sful on Sef1 activity (Figure 4C). These results indicate that induction of $S E F 1$ is tied to mitochondrial activity and underlines the ability of the mutant to adapt to iron deficient conditions. In aggregate, these observations suggest that (i) inhibition of Sef1 activity in iron-replete conditions require functional mitochondria and (ii) $\mathrm{Fe}-\mathrm{S}$ deficiency in $f z o 1 \Delta / \Delta$ 
may be the basis of the loss of iron-responsive regulation of Sef1 in C. albicans.

\section{Sef1 Is Retained in the Nucleus in fzo1 $\Delta / \Delta$}

To correlate the induced SEF1 expression to its protein level and localization in $f z 01 \Delta / \Delta$, we used an epitope-tagged version of Sef1 in which 13X-Myc epitope was fused in-frame at its C-terminus (Sef1-Myc). Immunoblotting with anti-Myc antibody was performed to measure the Sef1 protein levels. Previous reports demonstrate an inverse relationship between Sef1 protein levels and iron content in the growth medium (Chen and Noble, 2012). In line with this, the steady state level of Sef1-Myc was fivefold higher (quantified by ImageJ) in wild type cells grown in iron-deplete medium versus iron-replete medium (Figure 5A; lanes 2 and 3). Similarly, 6.6-fold high expression of Sef1-Myc was observed in $f z o 1 \Delta / \Delta$ cells propagated in irondeplete medium, compared to wild type in iron-replete medium (lanes 2 and 5). Strikingly, fzo $\Delta / \Delta$ cells in iron-replete condition exhibited sixfold higher Sef1 expression versus wild type cells in similar growth condition, indicating that the ability of Sef1 to sense cellular iron pools is impaired in cells with dysfunctional mitochondria (Figure 5A; lanes 4 and 2). The higher protein levels in the mutant correlated well with the induced SEF1 transcripts (Figure 4A), reaffirming the iron-starved status of $f z o 1 \Delta / \Delta$ cells even in iron sufficient condition.

Earlier studies have established that the localization of Sef1 varies as a function of iron wherein, Sef1 was localized primarily in the cytoplasm in iron-replete conditions and in the nucleus in iron-deplete conditions (Chen and Noble, 2012). To evaluate if Sef1 localization will vary as a function of mitochondrial activity, we performed indirect immunofluorescence microscopy on the wild type and $f z 01 \Delta / \Delta$ cells. As Sful is known to be retained in the cytoplasm in iron-deplete medium, Sfu1-Myc expressing wild type strain was used as a control for cytoplasmic localization (Chen and Noble, 2012; Supplementary Figure S2). The localization of Sef1-Myc protein in wild type cells varied as a function of iron as it was localized in both cytoplasm and nucleus in iron-replete cells and redirected to the nucleus in iron-deplete cells (Figure 5B). By comparison, Sef1-Myc was not only primarily localized to the nucleus in $f z 01 \Delta / \Delta$ cells in iron-deplete medium but it was retained in the nucleus even in the presence of iron in the medium, indicating that the subcellular partitioning of Sef1 in response to iron availability in the medium is countermanded by insufficient mitochondrial activity. Collectively, these results demonstrate that the high expression and nuclear retention of Sef1 in $f z o 1 \Delta / \Delta$ cells results in the constitutive activation of the iron regulon. We propose that inhibition of Sef1 activity under iron-replete conditions is dependent on a $\mathrm{Fe}-\mathrm{S}$ cluster pathway signal furnished by functional mitochondria in this pathogenic fungus.

\section{DISCUSSION}

This study signifies the role of mitochondria in iron sensing which is crucial for harmonizing mitochondrial iron usage

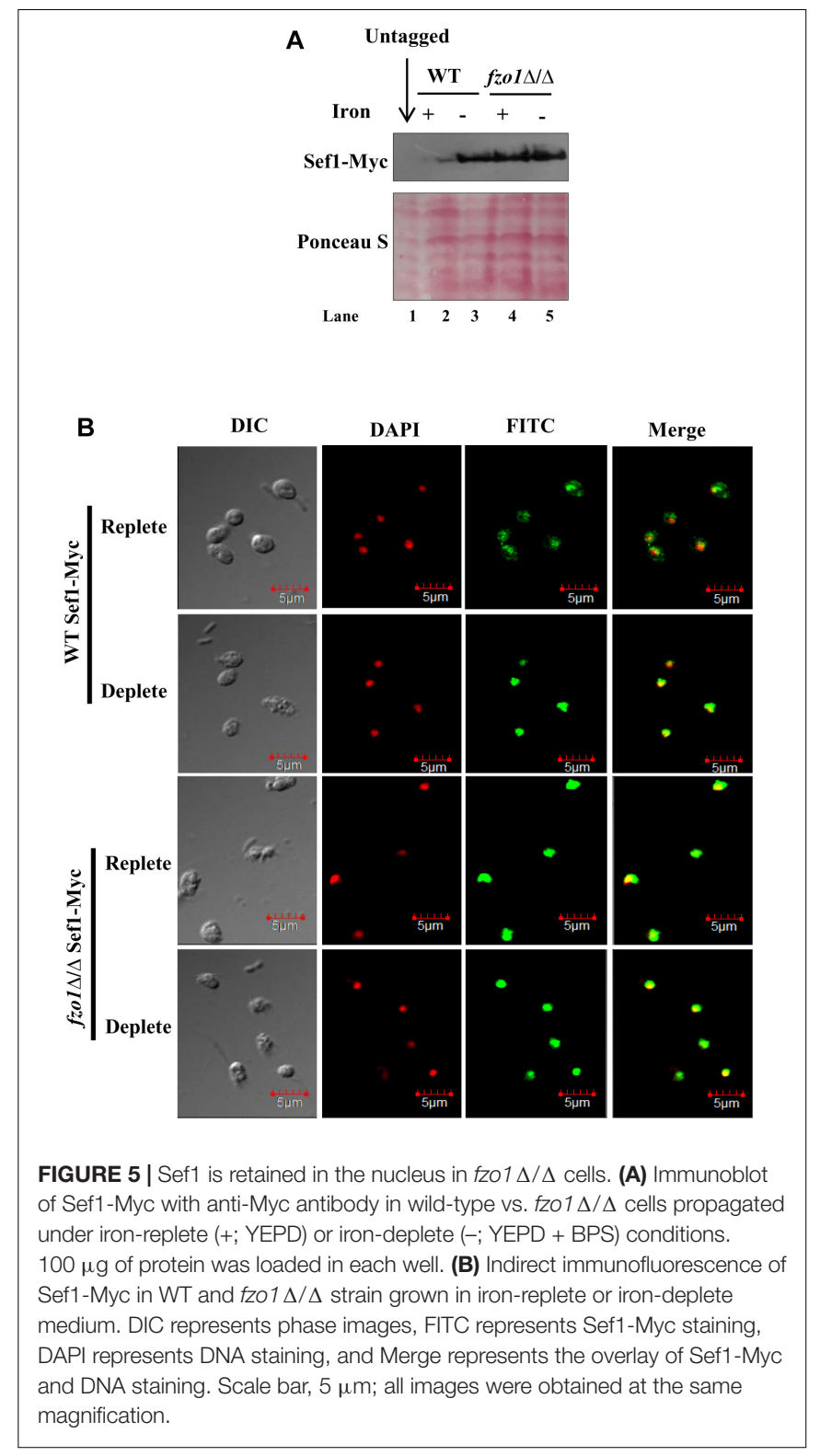

with cellular iron acquisition. Although the essentiality of mitochondria in regulating diverse cellular processes has been established, its role in regulating iron homeostasis in Sef1dependent manner, by serving as the focal point of $\mathrm{Fe}-\mathrm{S}$ biogenesis has not been addressed in C. albicans. Our use of $C$. albicans cells that harbor dysfunctional mitochondria $(f z o 1 \Delta / \Delta)$ enabled us to establish, for the first time a link between mitochondria-dependent $\mathrm{Fe}-\mathrm{S}$ cluster biosynthesis and iron sensing by the regulator, Sef1. Mitochondrial iron overload (Figure 2B) and abnormally elevated expression of iron regulon in growth medium containing sufficient iron denotes perturbed iron homeostasis and iron-starved status in $f z 01 \Delta / \Delta$ cells. This highlights that dysfunctional mitochondria impairs the iron responsiveness of iron regulon, such that the downregulation of the iron regulon genes in presence of sufficient iron is impeded. 
Defective Fe-S biosynthesis due to insufficient mitochondrial activity, as is evident from decreased aconitase activity (Figure 3A), might be a plausible basis for the loss of iron responsiveness of iron regulon in $f z 01 \Delta / \Delta$ cells. While aconitase protein levels were not analyzed in the present study, the transcript levels of ACO1 remain unchanged in the mutant (Supplementary Figure S1). We speculate that defective Fe-S cluster synthesis may be one of the basis for the decrease in aconitase activity in the mutant as reports in $S$. cerevisiae demonstrate that compromising $\mathrm{Fe}-\mathrm{S}$ cluster synthesis does not affect aconitase protein levels/stability (Chen et al., 2002; Gelling et al., 2008). The partial restoration of aconitase activity and expression of iron regulon genes to wild type level, upon overexpressing the core components involved in $\mathrm{Fe}-\mathrm{S}$ cluster synthesis, confirmed perturbed $\mathrm{Fe}-\mathrm{S}$ biogenesis as the basis of deregulated iron homeostasis in $f z o 1 \Delta / \Delta$ cells (Figures $3 B, C$ ). The transcriptional induction of C. albicans FET34 in the mutant will lead to high iron acquisition, irrespective of the iron content in the exogenous medium (Figures 2A, 6). Consequentially, increased cytosolic assimilation of iron will result in increased import of iron in the mitochondria via MRS4 resulting in mitochondrial iron overload in $f z o 1 \Delta / \Delta$ cells (Figures 2A,B). Despite increased iron levels in the mitochondria, the mutant fails to synthesize $\mathrm{Fe}-\mathrm{S}$ clusters due to defective $\mathrm{Fe}-\mathrm{S}$ synthesis machinery. Shortage in the production of $\mathrm{Fe}-\mathrm{S}$ clusters in $f z o 1 \Delta / \Delta$ may provide a signal to the nucleus indicating insufficient bioavailable iron for
$\mathrm{Fe}-\mathrm{S}$ biosynthesis, thus generating a cellular iron starvation status in these cells. The cellular response to the iron starved status in $f z o 1 \Delta / \Delta$ cells is the upregulation of the iron regulon, leading to mitochondrial iron overload, thus tying mitochondrial use of iron for $\mathrm{Fe}-\mathrm{S}$ synthesis to cellular iron obtainment in C. albicans (Figure 6).

Despite them being tied to iron sensing, whether Sef1 and Sful require additional regulatory inputs remains unanswered. Our findings established Sefl as the key component of the iron homeostasis regulatory circuit in $f z o 1 \Delta / \Delta$ cells based on (i) derepression of iron regulon genes (CCC2, FRE2, FRE31, and RBT5) (Figure 3C) that are otherwise regulated by Sef1 in iron-deplete conditions, (ii) the inability of the $\operatorname{sef} 1 \Delta / \Delta f z o 1 \Delta / \Delta$ cells to adapt to iron deficiency in the medium (Figure 4C), and (iii) increased Sef1 levels in $f z o 1 \Delta / \Delta$ during iron sufficiency (Figure 4A). Thereafter, based on the partial restoration of the SEF1 transcript level to wild type levels upon forced overexpression of ISU1 in $f z o 1 \Delta / \Delta$ (Figure 4B), prompted us to suggest that iron sensing by this regulator depends on a signal from mitochondria and particularly from mitochondrial $\mathrm{Fe}-\mathrm{S}$ cluster biogenesis in C. albicans. The iron-dependent localization of Sef1 was also affected in $f z 01 \Delta / \Delta$ cells; Sef1 was constitutively retained in the nucleus in iron-sufficient conditions (Figure 5B), arguing that mitochondrial-dependent $\mathrm{Fe}-\mathrm{S}$ synthesis is a determinant of Sef1 localization. Although, iron regulation in yeast and higher eukaryotes differ substantially (Craig and Marszalek, 2002; Rouault and Tong, 2005; Lill and Mühlenhoff, 2006), the

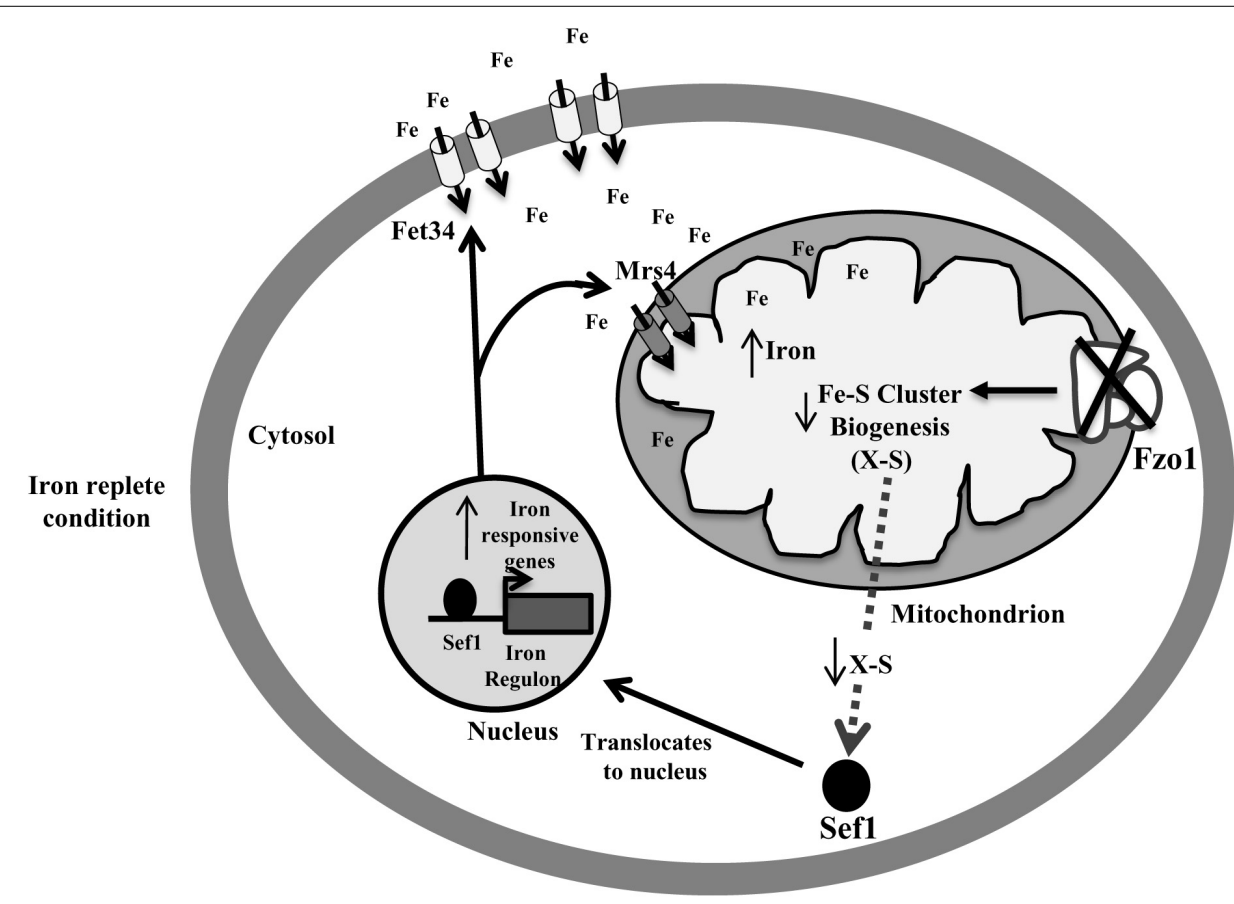

FIGURE 6 | Activation of Sef1 is dependent on mitochondrial Fe-S biogenesis. Loss of FZO1 leads to decreased Fe-S biogenesis, resulting in reduced activity of aconitase, a Fe-S cluster-containing protein. Decreased Fe-S biogenesis results in low Fe-S clusters and an unknown sulfur-containing compound (X-S) that may be exported into the cytosol. This unknown compound may be required for retaining Sef1 to the cytosol. Decreased level of compound X-S will signify iron starvation resulting in translocation of Sef1 to the nucleus. Consequentially, iron regulon genes including Fet34 and Mrs4 are activated leading to increased cytosolic iron acquisition followed by enhanced mitochondrial iron levels, in iron replete conditions. 
regulatory role of $\mathrm{Fe}-\mathrm{S}$ biogenesis system is almost conserved in vertebrates, as mice or humans depleted of Abcb7 (involved in export of mitochondrial synthesized Fe-S compound) and patients suffering with low levels of frataxin (allosteric activator of the Fe-S cluster synthesizing enzyme cysteine desulfurase, NFS1) display iron accumulation in affected tissues (Pondarré et al., 2006; Popescu et al., 2007). Interestingly, precedence for $\mathrm{Fe}-\mathrm{S}$ regulation of iron regulon expression is demonstrated by $S$. cerevisiae Aft1 that senses the status of $\mathrm{Fe}-\mathrm{S}$ cluster production and export for regulating its own expression and localization (Yamaguchi-Iwai et al., 1995, 1996; Chen et al., 2004). Likewise, the iron sensing regulators HapX and SreA of Aspergillus fumigatus sense $\mathrm{Fe}-\mathrm{S}$ cluster biogenesis to maintain iron homeostasis (Misslinger et al., 2018). This key molecule may be a $\mathrm{Fe}-\mathrm{S}$ cluster-containing protein or a by-product of $\mathrm{Fe}-$ $\mathrm{S}$ biogenesis produced along with $\mathrm{Fe}-\mathrm{S}$ clusters, which might be sensed by Sef1 or by a protein that associates with Sef1 for its activity (Figure 6). Aft 1 of $S$. cerevisiae contains a CXC motif that if mutated (C293F) might hinder Aft1 from binding to $\mathrm{Fe}-\mathrm{S}$, resulting in a constitutively active allele, indicating the potential of this motif to be involved in directly binding to $\mathrm{Fe}-\mathrm{S}$ cluster (Yamaguchi-Iwai et al., 1995; Chen et al., 2004). Sef1 is devoid of this motif but the possibility that this regulator may bind to another $\mathrm{Fe}-\mathrm{S}$ cluster-containing protein for iron sensing can explain the dependence of $C$. albicans iron regulon on $\mathrm{Fe}-\mathrm{S}$ cluster biosynthesis. Identification of the type of regulatory signal transduced from the mitochondria to Sef1 will decipher the mechanism underlying the cross-talk between mitochondrial $\mathrm{Fe}-\mathrm{S}$ cluster biogenesis pathway and iron responsiveness of Sef1.

Many important questions pertaining to how iron regulates the expression and cellular localization of Sef1 in C. albicans remain to be elucidated. The questions include whether iron sensing by Sef1 exclusively depends on a signal originating from the mitochondrial $\mathrm{Fe}-\mathrm{S}$ cluster synthesis or the cytosolic $\mathrm{Fe}-\mathrm{S}$ assembly (CIA) also is a key in this process. Another question that arises is whether cellular iron status in C. albicans is involved in regulating the import or the export of Sef1 into the nucleus. The CIA is shown to be dispensable for iron sensing in at least S. cerevisiae and A. fumigatus (Chen et al., 2004; Lill et al., 2012; Misslinger et al., 2018). Deleting components of the CIA will address the relevance of this assembly process for iron sensing in C. albicans. Iron starved environments in the mammalian host serve as location markers for pathogens, signaling their entry into the host by triggering the expression of virulence genes. Given the established role of Sef1 in coupling iron acquisition with the expression of genes required for virulence, calibrating the levels of Sef1 is requisite in this pathogenic fungus. This is achieved by subjecting Sef1 to a series of post-transcriptional regulations (Chen and Noble, 2012). Disruption of these regulatory events affects the pathogenesis of C. albicans in a mammalian model of disseminated infection (Chen et al., 2011). Here, we addon to the regulatory inputs in the form of mitochondrialdependent $\mathrm{Fe}-\mathrm{S}$ cluster biogenesis pathway that Sef1 perceives to activate the iron regulon for iron acquisition in the commensal-pathogen C. albicans. Multiple levels of regulation will assist in adjusting the activity of Sef1, thus empowering C. albicans to gauge and inhabit iron scarce and surfeit niches of the mammalian host.

\section{DATA AVAILABILITY}

Publicly available datasets were analyzed in this study. This data can be found here: https://www.ncbi.nlm.nih.gov/geo/query/acc. cgi? acc $=$ GSE46003.

\section{AUTHOR CONTRIBUTIONS}

SLP and SR planned the experiments and wrote the manuscript. SR performed the experiments and analyzed the data.

\section{FUNDING}

SLP acknowledges funding support from the SERB, Department of Science and Technology, Government of India, under the umbrella project DST-PURSE awarded to the Jawaharlal Nehru University, as well as Capacity Build-up, UGCResource Networking and UGC-SAP awarded to the Jawaharlal Nehru University. SR acknowledges the Council for Scientific and Industrial Research, for awarding junior and senior research fellowships.

\section{ACKNOWLEDGMENTS}

We gratefully acknowledge Joachim Morschhauser and Suzanne Noble for providing us with the plasmids and strains used in this study and to the entire lab for insightful discussions. We also thank Steven Claypool, Jeśus Pla, and Alok Mondal for critical reading of the manuscript. We acknowledge the technical assistance from Ashok Sahu at the Advanced Instrumentation Research Facility (AIRF), the Jawaharlal Nehru University (JNU) for performing confocal microscopy and the Department of Biochemical Engineering and Biotechnology, Indian Institute of Technology (IIT) Delhi for providing facility of ICP-MS.

\section{SUPPLEMENTARY MATERIAL}

The Supplementary Material for this article can be found online at: https://www.frontiersin.org/articles/10.3389/fmicb.2019. 01528/full\#supplementary-material

FIGURE S1 | Expression of $A C O 1$ in $f z 01 \Delta / \Delta$ in iron replete condition. The mRNA level of $A C O 1$ was quantified by qPCR in $f z 01 \Delta / \Delta$ and fzo $1 \Delta / \Delta+F Z O 1$ relative to wild type. ACT1 was used as internal control and data shown are mean $\pm \mathrm{SD}$ $(n=3)$.

FIGURE S2 | Localization of Sef1 and Sfu1-Myc in iron deplete condition. Shown images are indirect immunofluorescence of Sef1-Myc and Sfu1-Myc expressed in wild type, in iron-deplete (YEPD + BPS) condition. DIC represents phase images, FITC represents Sef1-Myc staining, DAPI represents DNA staining, and Merge 
represents the overlay of Sef1-Myc and DNA staining. Scale bar, $5 \mu \mathrm{m}$; all images were obtained at the same magnification.

TABLE S1 | Candida albicans strains used in this study.

TABLE S2 | Plasmids used in the study.

\section{REFERENCES}

Bellí, G., Molina, M. M., García-Martínez, J., Pérez-Ortín, J. E., and Herrero, E. (2004). Sacharomyces cerevisiae glutaredoxin 5-deficient cells subjected to continuous oxidizing conditions are affected in the expression of specific sets of genes. J. Biol. Chem. 279, 12386-12395. doi: 10.1074/jbc. M311879200

Brown, G. D., Denning, D. W., Gow, N. A. R., Levitz, S. M., Netea, M. G., and White, T. C. (2012). Hidden killers: human fungal infections. Sci. Transl. Med. 4:165rv13. doi: 10.1126/scitranslmed.3004404

Chen, C., and Noble, S. M. (2012). Post-transcriptional regulation of the sef1 transcription factor controls the virulence of candida albicans in its mammalian host. PLoS Pathog. 8:e1002956. doi: 10.1371/journal.ppat. 1002956

Chen, C., Pande, K., French, S. D., Tuch, B. B., and Noble, S. M. (2011). An iron homeostasis regulatory circuit with reciprocal roles in Candida albicans commensalism and pathogenesis. Cell Host Microbe 10, 118-135. doi: 10.1016/ j.chom.2011.07.005

Chen, O. S., Crisp, R. J., Valachovic, M., Bard, M., Winge, D. R., and Kaplan, J. (2004). Transcription of the yeast iron regulon does not respond directly to iron but rather to iron-sulfur cluster biosynthesis. J. Biol. Chem. 279, 29513-29518. doi: 10.1074/jbc.M403209200

Chen, O. S., Hemenway, S., and Kaplan, J. (2002). Inhibition of fe-s cluster biosynthesis decreases mitochondrial iron export: evidence that yfh $1 \mathrm{p}$ affects fes cluster synthesis. Proc. Natl. Acad. Sci. U.S.A. 99, 12321-12326. doi: 10.1073/ pnas. 192449599

Craig, E. A., and Marszalek, J. (2002). A specialized mitochondrial molecular chaperone system:a role in formation of Fe/S centers. Cell. Mol. Life Sci. 59, 1658-1665. doi: 10.1007/PL00012493

Demuyser, L., Swinnen, E., Fiori, A., Herrera-Malaver, B., Vestrepen, K., and Van Dijck, P. (2017). Mitochondrial cochaperone mgel is involved in regulating susceptibility to fluconazole in Saccharomyces cerevisiae and Candida species. mBio 8:e00201-17. doi: 10.1128/mBio.00201-17

Dong, Y., Zhang, D., Yu, Q., Zhao, Q., Xiao, C., Zhang, K., et al. (2017). Loss of Ssq1 leads to mitochondrial dysfunction, activation of autophagy and cell cycle arrest due to iron overload triggered by mitochondrial iron-sulfur cluster assembly defects in Candida albicans. Int. J. Biochem. Cell Biol. 85, 44-55. doi: 10.1016/j.biocel.2017.01.021

Fourie, R., Kuloyo, O. O., Mochochoko, B. M., Albertyn, J., and Pohl, C. H. (2018). Iron at the centre of Candida albicans interactions. Front. Cell. Infect. Microbiol. 8:185. doi: 10.3389/fcimb.2018.00185

Foury, F., and Talibi, D. (2001). Mitochondrial control of iron homeostasis: a genome wide analysis of gene expression in a yeast frataxindeficient strain. J. Biol. Chem. 276, 7762-7768. doi: 10.1074/jbc.M0058 04200

Garland, S. A., Hoff, K., Vickery, L. E., and Culotta, V. C. (1999). Saccharomyces cerevisiae ISU1 and ISU2: members of a well-conserved gene family for ironsulfur cluster assembly. J. Mol. Biol. 294, 897-907. doi: 10.1006/jmbi.1999. 3294

Gelling, C., Dawes, I. W., Richhardt, N., Lill, R., and Mühlenhoff, U. (2008). Mitochondrial Iba57p is required for Fe/S cluster formation on aconitase and activation of radical SAM enzymes. Mol. Cell. Biol. 28, 1851-1861. doi: 10.1128/ MCB.01963-07

Gillum, A. M., Tsay, E. Y., and Kirsch, D. R. (1984). Isolation of the Candida albicans gene for orotidine-5'-phosphate decarboxylase by complementation of S. cerevisiae ura3 and E. coli pyrF mutations. Mol. Gen. Genet. 198, 179-182. doi: $10.1007 /$ bf00328721

Hausmann, A., Samans, B., Lill, R., and Mühlenhoff, U. (2008). Cellular and mitochondrial remodeling upon defects in iron-sulfur protein biogenesis. J. Biol.Chem. 283, 8318-8330. doi: 10.1074/jbc.M70557 0200
TABLE S3 | Oligonucleotides used in this study.

TABLE S4 | Differentially regulated genes associated with iron uptake/acquisition in $f 201 \Delta / \Delta$ and regulated by transcription factors Sef1, Sfu1, and Hap43.

TABLE S5 | Specific aconitase activity of strains used in Figures 3A,B.

Hermann, G. J., Thatcher, J. W., Mills, J. P., Hales, K. G., Fuller, M. T., Nunnari, J., et al. (1998). Mitochondrial fusion in yeast requires the transmembrane GTPase Fzo1p. J. Cell Biol. 143, 359-373. doi: 10.1083/jcb.143.2.359

Inglis, D. O., and Johnson, A. D. (2002). ash1 protein, an asymmetrically localized transcriptional regulator, controls filamentous growth and virulence of Candida albicans. Mol. Cell. Biol. 22, 8669-8680. doi: 10.1128/MCB.22.24.8669-8680. 2002

Kispal, G., Csere, P., Prohl, C., and Lill, R. (1999). The mitochondrial proteins Atmlp and Nfs1p are essential for biogenesis of cytosolic Fe/S proteins. EMBO J. 18, 3981-3989. doi: 10.1093/emboj/18.14.3981

Li, D., Chen, H., Florentino, A., Alex, D., Sikorski, P., Fonzi, W. A., et al. (2011). Enzymatic dysfunction of mitochondrial complex I of the Candida albicans goal mutant is associated with increased reactive oxidants and cell death. Eukaryotic Cell 10, 672-682. doi: 10.1128/EC.00303-10

Lill, R., Hoffmann, B., Molik, S., Pierik, A. J., Rietzschel, N., Stehling, O., et al. (2012). The role of mitochondria in cellular iron-sulfur protein biogenesis and iron metabolism. Biochim. Biophys. Acta. 1823, 1491-1508. doi: 10.1016/ j.bbamcr.2012.05.009

Lill, R., and Mühlenhoff, U. (2006). Iron-sulfur protein biogenesis in eukaryotes: components and mechanisms. Annu. Rev. Cell Dev. Biol. 22, 457-486. doi: 10.1146/annurev.cellbio.22.010305.104538

Martin, R. B., Savory, J., Brown, S., Bertholf, R. L., and Wills, M. R. (1987). Transferrin binding of $\mathrm{Al} 3+$ and Fe3+. Clin. Chem. 33, 405-407.

McCance, R. A., and Widdowson, E. M. (1938). The absorption and excretion of iron following oral and intravenous administration. J. Physiol. 94, 148-154. doi: 10.1113/jphysiol.1938.sp003669

Miret, S., Simpson, R. J., and McKie, A. T. (2003). Physiological and mlecular biology of dietary iron absorption. Ann. Rev. Nutr. 23, 283-301.

Misslinger, M., Lechner, B. E., Bacher, K., and Haas, H. (2018). Ironsensing is governed by mitochondrial, not by cytosolic iron-sulfur cluster biogenesis in Aspergillus fumigatus. Metallomics 10, 1687-1700. doi: 10.1039/ C8MT00263K

Mozdy, A. D., and Shaw, J. M. (2003). A fuzzy mitochondrial fusion apparatus comes into focus. Nat. Rev. Mol. Cell Biol. 4, 468-478. doi: 10.1038/ nrm 1125

Muzzey, D., Schwartz, K., Weissman, J. S., and Sherlock, G. (2013). Assembly of a phased diploid Candida albicans genome facilitates allele-specific measurements and provides a simple model for repeat and indel structure. Genome. Biol. 14:R97. doi: 10.1186/gb-2013-14-9-r97

Nobile, C. J., Nett, J. E., Hernday, A. D., Homann, O. R., Deneault, J.-S., Nantel, A., et al. (2009). Biofilm matrix regulation by Candida albicans Zap1. PLoS Biol. 7:e1000133. doi: 10.1371/journal.pbio.1000133

Nobile, C. J., Schneider, H. A., Nett, J. E., Sheppard, D. C., Filler, S. G., Andes, D. R., et al. (2008). Complementary adhesin function in C. albicans biofilm formation. Curr. Biol. 18, 1017-1024. doi: 10.1016/j.cub.2008.06.034

Noble, S. M., French, S., Kohn, L. A., Chen, V., and Johnson, A. D. (2010). Systematic screens of a Candida albicans homozygous deletion library decouple morphogenetic switching and pathogenicity. Nat. Genet. 42, 590-598. doi: $10.1038 /$ ng.605

Noble, S. M., and Johnson, A. D. (2005). Strains and strategies for large-scale gene deletion studies of the diploid human fungal pathogen Candida albicans. Eukaryot. cell 4, 298-309. doi: 10.1128/ec.4.2.298-309.2005

Patil, V. A., Fox, J. L., Gohil, V. M., Winge, D. R., and Greenberg, M. L. (2013). Loss of cardiolipin leads to perturbation of mitochondrial and cellular iron homeostasis. J. Biol. Chem. 288, 1696-1705. doi: 10.1074/jbc.M112. 428938

Pierik, A. J., Netz, D. J. A., and Lill, R. (2009). Analysis of iron-sulfur protein maturation in eukaryotes. Nat. Protoc. 4, 753-766. doi: 10.1038/nprot. 2009.39

Pondarré, C., Antiochos, B. B., Campagna, D. R., Clarke, S. L., Greer, E. L., Deck, K. M., et al. (2006). The mitochondrial ATP-binding cassette transporter Abcb7 
is essential in mice and participates in cytosolic iron-sulfur cluster biogenesis. Hum. Mol. Genet. 15, 953-964. doi: 10.1093/hmg/ddl012

Popescu, B. F. Gh, Pickering, I. J., George, G. N., and Nichol, H. (2007). The chemical form of mitochondrial iron in Friedreich's ataxia. J. Inorg. Biochem. 101, 957-966. doi: 10.1016/j.jinorgbio.2007. 03.004

Rappaport, L., Oliviero, P., and Samuel, J. L. (1998). Cytoskeleton and mitochondrial morphology and function. Mol. Cell. Biochem. 184, 101-105. doi: 10.1007/978-1-4615-5653-4_8

Rouault, T. A., and Tong, W.-H. (2005). Iron-sulphur cluster biogenesis and mitochondrial iron homeostasis. Nat. Rev. Mol. Cell Biol. 6, 345-351. doi: 10. $1038 / \mathrm{nrm} 1620$

Rutherford, J. C., Ojeda, L., Balk, J., Mühlenhoff, U., Lill, R., and Winge, D. R. (2005). Activation of the iron regulon by the yeast aft1/aft2 transcription factors depends on mitochondrial but not cytosolic iron-sulfur protein biogenesis. J. Biol. Chem. 280, 10135-10140. doi: 10.1074/jbc.M4137 31200

Thomas, E., Roman, E., Claypool, S., Manzoor, N., Pla, J., and Panwar, S. L. (2013). Mitochondria influence $c d r 1$ efflux pump activity, hog1-mediated oxidative stress pathway, iron homeostasis, and ergosterol levels in Candida albicans. Antimicrob. Agents Chemother. 57, 5580-5599. doi: 10.1128/AAC.00889-13 van het Hoog, M., Rast, T. J., Martchenko, M., Grindle, S., Dignard, D., Hogues, H., et al. (2007). Assembly of the Candida albicans genome into sixteen supercontigs aligned on the eight chromosomes. Genome Biol. 8:R52. doi: 10. 1186/gb-2007-8-4-r52

Yamaguchi-Iwai, Y., Dancis, A., and Klausner, R. D. (1995). AFT1: a mediator of iron regulated transcriptional control in Saccharomyces cerevisiae. EMBO J. 14, 1231-1239. doi: 10.1002/j.1460-2075.1995.tb07106.x

Yamaguchi-Iwai, Y., Stearman, R., Dancis, A., and Klausner, R. D. (1996). Ironregulated DNA binding by the Aft1 protein controls the iron regulon in yeast. EMBO J. 15, 3377-3384. doi: 10.1002/j.1460-2075.1996.tb00703.x

Conflict of Interest Statement: The authors declare that the research was conducted in the absence of any commercial or financial relationships that could be construed as a potential conflict of interest.

Copyright (c) 2019 Ror and Panwar. This is an open-access article distributed under the terms of the Creative Commons Attribution License (CC BY). The use, distribution or reproduction in other forums is permitted, provided the original author(s) and the copyright owner(s) are credited and that the original publication in this journal is cited, in accordance with accepted academic practice. No use, distribution or reproduction is permitted which does not comply with these terms. 